\title{
Organização do Processo de Trabalho na Estratégia Saúde da Família: Contribuições do Programa de Valorização da Atenção Básica-Provab no Ceará
}

\author{
Brilhante, Ana Paula Cavalcante Ramalho; Gomes, Kilma Wanderley Lopes; Lopes, \\ Luana Bezerra; Arruda, Francisca Lucia Nunes de; Justa, Ana Virginia de Castro da \\ Secretaria da Saúde do Estado do Ceará - apcrbrilhante@gmail.com
}

\begin{abstract}
INTRODUÇÃO: a Atenção Básica como Rede de Atenção à Saúde estruturante do SUS tem sido assumida pelo Ministério da Saúde- MS com prioridade. Entre os desafios refere o acesso e acolhimento, à efetividade, à resolutividade das suas práticas, ao recrutamento, provimento e fixação de profissionais, a capacidade de gestão, coordenação do cuidado (BRASIL, 2012). no ano de 2003, o MS criou a Política Nacional de Humanização (PNH), com um dos objetivos enfrentar problemas no campo da organização e da gestão do trabalho em saúde (PASCHE et. , 2011). para a viabilização dos princípios e resultados esperados com o HumanizaSUS, a PNH opera com diferentes dispositivos, entendidos como "tecnologias" ou "modos de fazer", entre eles o acolhimento com avaliação ou classificação de risco. Segundo o Ministério da Saúde, a humanização é entendida pela valorização dos diferentes sujeitos implicados no processo de produção de saúde (BRASIL, 2004). OBJETIVO: Relatar a experiência da implantação do acolhimento com avaliação de risco e vulnerabilidade em uma Unidade de Saúde da Família do interior do Ceará. METODOLOGIA: Inicialmente realizou-se reunião com os médicos do PROVAB, supervisora, representantes da comissão estadual coordenadora do programa e gestores local após avaliação dos problemas detectados. no segundo momento foi realizado reunião com a supervisora e toda a equipe para apresentação da proposta e pactuação da realização de oficina de acolhimento com avaliação de risco e vulnerabilidade. a equipe foi organizada em três grupos: Acolhimento e organização da agenda, saúde materno infantil, visita domiciliar e atenção ao paciente com hipertensão arterial e diabetes mellitus. para desencadear as discussões, foram levantadas questões norteadoras. Após discussões nos grupos, foram apresentados os produtos. RESULTADOS: Pactuação quanto a organização da agenda; Agentes Comunitários de Saúde-ACS encarregados de orientar a comunidade sobre o atendimento de acordo com a agenda proposta; acolhimento com avaliação de risco e vulnerabilidade realizado pela enfermeira; reunião mensal para avaliação e planejamento do mês seguinte com toda a equipe; realização de atendimento dos grupos prioritários, seguindo as orientações do MS; agendamento de atendimento nas áreas distantes. na primeira avaliação realizada percebeu-se melhoria na organização do processo de trabalho da equipe, satisfação de todos os trabalhadores de saúde, em especial do ACS, pois sentiram maior valorização em serem incluídos na organização do serviço. CONCLUSÃO: Torna-se necessário que as equipes possam refletir e analisar seu processo de trabalho, de modo que garanta o acesso da população aos serviços de saúde na Atenção Básica. Ressaltamos que as experiências de acolhimento de fato vivenciadas no cotidiano também dos trabalhadores precisam ser percebidas como produtor de cuidado para eles e para os usuários, assim poderão defender o acolhimento como dispositivo de fundamental importância para todos.
\end{abstract}

Brilhante, Ana Paula Cavalcante Ramalho; Gomes, Kilma Wanderley Lopes; Lopes, Luana Bezerra; Arruda, Francisca Lucia Nunes de; Justa, Ana Virginia de Castro da. Organização do Processo de Trabalho na Estratégia Saúde da Família: Contribuições do Programa de Valorização da Atenção Básica-Provab no Ceará.. In: Anais do Congresso Internacional de Humanidades \& Humanização em Saúde [= Blucher Medical Proceedings, num.2, vol.1]. São Paulo: Editora Blucher, 2014. ISSN 2357-7282

DOI 10.5151/medpro-cihhs-10267 